\title{
Geminates and Picard Pronominal Clitic Allomorphy*
}

\author{
Brian José
}

Indiana University. Department of Linguistics

Bloomington, Indiana 47405 (USA)

bjose@alumni.indiana.edu

\section{Julie Auger}

Indiana University. Department of French \& Italian and Department of Linguistics Bloomington, Indiana 47405 (USA)

jauger@indiana.edu

\section{Abstract}

In this paper, we examine five pronominal clitics in Vimeu Picard with a geminate-consonant allomorph. Assuming a doubly-linked (non-moraic) representation of geminates, we attribute the four different patterns observed to four different underlying structures serving as inputs to an OT constraint ranking. The $1 \mathrm{sg}$ and $2 \mathrm{sg}$ pronouns are singletons which are subject to gemination in one specific position, syllable structure permitting. The 3 sg pronoun is a geminate which is subject to variable degemination or vowel epenthesis where there are insufficient syllable slots to accommodate it. The partitive/genitive is somewhere in between a singleton and a geminate (its $\mathrm{UR}$ is $/ \mathrm{n}^{\mathrm{n}} /$, where the superscript «n» represents a floating nasal; it may surface as [nn] or as [ñ̃], depending upon where its floating nasal docks). Finally, the $3 \mathrm{pl}$ is neither a singleton nor a geminate underlyingly, but becomes a geminate by its first segment assimilating to its second.

Key words: appendix, cross-syllabification, degemination, positional alignment, stressed lengthening, stochastic Optimality Theory, Sympathy Theory, variation, vowel epenthesis; Picard.

\section{Table of Contents}

\section{Introduction 4. Conclusion}

2. Theoretical and empirical issues References

3. Four patterns analyzed

* This research is supported by NSF grant number BCS-0091687 to the second author. We are grateful to the audiences at the 12th Annual Indiana University French \& Italian Graduate Student Colloquium and the 33rd Linguistic Symposium on Romance Languages (LSRL 33), where earlier versions of this analysis were presented, and to an anonymous reviewer for their comments. The analysis has further benefited from discussions with Clancy Clements, Marie-Hélène Côté, Stuart Davis, Caitlin Dillon, Daniel Dinnsen, Heather Goad, Bruce Hayes, John McCarthy, Kathryn Tippetts, and Barbara Vance and from help with the data from Jean-Pierre Calais, Jehan Vasseur, and Jean-Luc Vigneux. Finally, we are indebted to the CatJL editors, Jesús Jiménez and MariaRosa Lloret, for their sizeable investment in proofreading our manuscript and correcting the mistakes, both big and small, in it. The normal disclaimers apply. 


\section{Introduction}

A growing body of literature has found that the numerous forms that certain pronominal clitics take on in various Romance languages can all be derived from a single underlying form per pronoun, with the alternations being due to such factors as surrounding phonetic context, syllable structure, the presence or absence of other clitics, and so forth (cf., e.g., Bonet and Lloret 2005 for Catalan; Popescu 2000 for Romanian). In this paper, we show that pronominal clitic allomorphy in Vimeu Picard (henceforth VP) is another such case. ${ }^{1}$ Our focus here, however, is limited; we do not examine all of the VP pronominal clitics, only those which have a geminate consonant allomorph. We will see that while a unique underlying form can be posited for each of the clitics in question, a different type of structure must be posited in each of the four cases that we consider. Thus, we see that what are simply geminates in a language can, in fact, be quite diverse underlyingly, offering another view of Ham's (2001: 12) claim that "all geminates within a given language may not have a unified phonological representation". Each of these diverse structures is subjected to an OT constraint ranking (Prince and Smolensky 2004) which results in gemination, in geminate maintenance, or in degemination, thereby deriving the attested alternations.

In this paper, we consider four cases in particular: a) the $1 \mathrm{sg}$ and $2 \mathrm{sg}$ accusative/dative/reflexive pronouns, b) the $3 \mathrm{sg}$ accusative pronoun, c) the $3 \mathrm{pl}$ accusative pronoun, and d) the partitive/genitive pronoun. Representative examples, introducing the relevant allomorphy, are presented in (1)-(5). While the alternations of primary interest in this paper are between a geminate and a singleton consonant, as in (1)-(3), any analysis of this alternation must also take into account two other clitics that have a geminate allomorph: the $3 \mathrm{pl}$ accusative pronoun and the partitive/genitive pronoun. The $3 \mathrm{pl}$ pronoun in (4), unlike the singular pronouns in (1)(3), consistently surfaces as a geminate (e.g., *si j'z érouos déquértchès would not be possible for (4b)). Finally, the partitive/genitive pronoun in (5) (cf. Catalan, French $e n$; Italian $n e$ ) is of interest because it exhibits a different type of alternation altogether; here, instead of a geminate $\sim$ singleton opposition, we find $[\mathrm{nn}] \sim[\mathrm{n} \tilde{\varepsilon}]$.

(1) $1 \mathrm{sg}$ accusative/dative

a. Tues mmé, [ty mme] si tu veux. kill me-ACC if you want 'Kill me if you want to.'

b. Acoute mé bien, [akut me bjẽ ] Dorine. listen me-DAT well, Doreen 'Listen to me good, Doreen.'

1. Picard is a Romance language very closely related to French and spoken in parts of northern France and southern Belgium. The Vimeu variety is spoken in France's Somme département and is bounded by the Somme River to the north, the Bresle River and Normandy to the south, departmental highway 901 to the east, and the English Channel to the west. 
(2) 2 sg accusative/dative/reflexive

a. Assis tté leu[asi tte lø] su ch'banc. sit you-REFL there on that bench

'Sit here on this bench.'

b. Dépéque té [depek te] d'évnir. hurry you-REFL of to-come

'Come quick.'

(3) 3 sg accusative
a. $\mathrm{O} \quad 1 \mathrm{l}^{\prime}$
avoéme [o ll avwẽm] aveuc nous
we 3 sg-ACC had
with us
'It [the wind] was at our backs.'
b. J' l' avoais [3 lavwe] intindue dire... I 3sg-ACC had heard to-say 'I had heard her say...'

(4) 3 pl accusative
a. Pétète qu'a zz' éroait [ka zz erwe] acatès. maybe that she 3pl-ACC would-have bought 'Maybe she would have bought them.'
b. $\mathrm{Si}$ jé $\mathrm{zz}$ érouos [si ze zz erwo] déquértchès.
if I 3pl-ACC would-have unloaded
'If I had unloaded them.'

(5) Partitive/genitive
a. J' énn' ai foait [zẽ nn e fwe].
I PART AUX made
'I made some.'

b. Cho'f fille blonde a nin rioait [a nẽ riwe]. the girl blonde she PART was-laughing 'The blonde girl was laughing about it.'

We describe the data more fully in the next section (\$2.2); there, we also address the representation of geminates that we assume in this paper $(\$ 2.1)$. We present our analysis in $\S 3$. Finally, we conclude in $\S 4$.

\section{Theoretical and empirical issues}

We begin this section by identifying the representation of geminates that we adopt in the analysis to follow (\$2.1). Then we expand on our superficial presentation of the data above, including a description of pronoun-specific distributional idiosyncrasies (\$2.2). 


\subsection{The representation of geminates}

In this paper, we assume a doubly-linked representation of geminates instead of a possible, and arguably more popular, alternative: the moraic representation (e.g., Hayes 1989). The pros and cons of these two views and the history of the debate have been discussed extensively in the literature, and we will not repeat those arguments here (cf., e.g., Broselow 1995; Curtis 2003: 30-58; Ham 2001: 6-15; Kraehenmann 2003: 13-27). Suffice it to say that the debate persists even to this day. ${ }^{2}$ Possible doubly-linked representations include a single root node linked to two skeletal slots (e.g., McCarthy 1979), or a single set of phonological features linked to two root nodes (Selkirk 1990). Because we believe it to have been amply demonstrated - particularly in the framework of Prosodic Morphology (McCarthy and Prince 1986; but also cf. Selkirk 1990) — that there is no need to posit a skeletal tier as part of the prosodic hierarchy, we opt for the latter of these two doublylinked representations here. It should be understood, though, that by adopting a Rt-Rt representation of geminates, we are not arguing against the moraic representation. Rather, our reasons for treating geminates as Rt-Rt —or, more precisely, for not treating them as moraic - are twofold. First, we can find no evidence of any weight-sensitive phenomena in VP which would allow us to argue for or against the moraic representation of geminates in this language. ${ }^{3}$ Second, with respect to syllabification and vowel epenthesis, geminates pattern much like unsyllabifiable consonant clusters, a result which is difficult to obtain if geminates are single but moraic segments, but which follows straightforwardly if they are doublylinked segments.

Next, we turn to a more thorough examination of the data. This will reveal the various positions where geminates can occur in VP - initially, medially, and finally - and it will demonstrate the similarities between geminates and clusters, both of which require two syllable positions, thereby underscoring the attraction of the Rt-Rt representation.

\subsection{Data and overview of the problem}

The data described here and analyzed in $\$ 3$ is taken from a corpus of written Picard texts supplemented with native-speaker intuitions. For arguments defending the use of written data for phonological analyses (in VP), see Auger (2001: 259-262).

2. One representation that seems to have gone by unnoticed in these debates is Schmidt's (1992) hybrid representation in which geminates are both doubly-linked and moraic. While we do not find the specific arguments that she offers in favor of her segmental-moraic representation over a simply moraic representation to be particularly compelling (also cf. Curtis' 2003: 306-309 criticisms of the composite model as implemented by others), we nonetheless think that it is an intriguing hypothesis. It is also interesting that the two-root representation is not incompatible with mora projection (Selkirk 1990: 127), that Curtis (2003) does, in fact, combine Selkirk's two-root representation with moras, and that Muller (2002) arrives at a very similar skeletal and moraic representation as Schmidt, all of which attest to the appeal of such a hybrid representation or composite model.

3. For languages where there is evidence that geminates contribute to syllable weight, we have adopted Moraic Theory (José forthcoming). 
Also note that Auger found written Picard to be largely representative of the spoken language with respect to both a phonological variable (Auger 2002) and a series of grammatical variables (Auger 2003a). The question at hand is what this written data tells us about VP pronominal clitic allomorphy and the distribution of geminate consonant forms and non-geminate forms. We begin, though, with a general description of VP syllable structure.

\subsubsection{Syllable structure and consonant clusters}

The phonotactics of VP allow for fairly complex syllable structures. For instance, complex onsets are possible as long as sonority rises from the first segment to the second, the two segments do not occupy adjacent levels on the sonority hierarchy, and they have different places of articulation. Also, complex nuclei are possible as long as they are «light monomoraic diphthongs» (Steele and Auger 2002: 320), e.g., [wV] as in ploéyon [plwe.jõ] 'flexible branch' or [ui] as in pluie [plui] 'rain'. Finally, complex codas are possible word-finally as long as the first segment is a liquid and the second is less sonorous (e.g., pérle [perl] 'speaks').

If consonants that cannot be properly syllabified according to the preceding phonotactic requirements come together, then some repair strategy must be invoked. The phonology of VP offers four possibilities. The first one, cross-syllabification, allows a word-initial consonant to be syllabified as the coda of a preceding vowelfinal syllable, as in passeu dvant [pa.sød.vã] 'to pass in front of', or a word-final consonant to be syllabified as the onset of a following vowel-initial syllable, as in un triste étot [õ.tris.te.to] 'a sad state'. The second possibility is vowel epenthesis. An example of this is when a word like $d v a n t$, with an illicit initial cluster, follows a consonant-final word such as s'assir 'to sit down': s'assir édvant [sa.si.red.vã] 'to sit down in front of'. The third possibility is deletion. This occurs almost exclusively with final (rising sonority) obstruent-liquid clusters; in such cases, the liquid is deleted (e.g., /øtr/ $\rightarrow$ [øt] eute 'other'; cf. eutrémint [ø.tre.mẽ] 'otherwise'). The fourth possibility, indirect licensing, is only available at the edges of prosodic boundaries. Examples of this are when a cluster like [dv] occurs at the beginning of an Utterance (Utt) or Intonational Phrase (IntPhr), as in Dvant qu'éch co i cante [dvã ke J ko i kãt] 'Before the cock crows', or when a cluster like [st] occurs at the end of a Prosodic Word (PrWord), as in a fzoait juste [a fzwe 3yst] 'it was close'. In these cases, the most marginal consonant in the cluster can be licensed by one of these higher levels of prosodic structure instead of the syllable. The actual licensing strategy employed in such contexts varies, though (see Auger 2000, 2001; Steele and Auger 2002). Of more relevance here is that there are important differences between initial and final appendices. For one thing, they are not licensed at the same levels; as indicated above, initial appendices are licensed by only the highest levels of prosodic structure (the Utt and the IntPhr), while final appendices are licensed by levels as low as the PrWord. Also, while any consonant can be licensed as an initial appendix, the only possible final appendices are the voiceless stops.

Returning, now, to the specific question of geminates, we first provide general observations about where they occur in VP $(\$ 2.2 .2)$ and then we address issues specific to the particular clitics analyzed here $(\$ 2.2 .3)$. 


\subsubsection{Geminates: general observations}

In VP, as in most other languages, geminates tend to occur in intervocalic position. The examples in (1)-(5), above, illustrate this issue. Here, the first half of the geminate is syllabified as a coda and the second half of it is syllabified as an onset. This preference for intervocalic ambisyllabicity is certainly understandable, considering the phonotactic restrictions on complex onsets and codas introduced at the beginning of \$2.2.1: since geminates consist of two root nodes sharing a single feature geometric structure, they cannot respect sonority sequencing requirements for complex onsets and codas. This forces us to ask, then, how it is that VP, rather atypically, also allows geminates in phrase-initial and phrase-final positions. Examples are provided in (6) and (7), respectively. The answer resides in our fourth possibility for handling illicit clusters: indirect licensing. That is, in these positions one half of the geminate is licensed as an appendix by a higher level of prosodic structure, as discussed above with respect to clusters. So, the two halves of the geminates in (6) constitute appendix-onset sequences and in (7), coda-appendix sequences. We should point out, though, that forms such as those in (7) with final geminates are the exception rather than the rule. Not only is there a general prohibition against final geminates in VP, but even with post-verbal clitics (the only possible exception to this prohibition) final geminates are allowed only when they convey emphatic stress. ${ }^{4}$ In these cases, the $[\mathrm{mm}]$ of (7a) violates constraints against final geminates and $[\mathrm{m}]$-appendices (the voiceless stops, again, being the only possible word-final appendices in VP) while the [tt] of (7b) violates the constraint against final geminates. Both of these states of affairs are presumably achieved by ranking an emphasis constraint, call it *WEAK-IN-STRONG/EMPHATICSTRESS (see $\S 3.2)$, above these constraints. ${ }^{5}$

4. That phrase-final geminates are restricted to clitics in post-verbal position is evident in the following examples. Here, we see that the $/ \mathrm{tt} /$ of $3 \mathrm{pl}$ verbal inflection surfaces as [tt] when phraseinternally, as in (i) and (ii), but as [t] when phrase-finally, as in (iii).

(i) Il avoait't acatè [i.la.vwet.ta.ka.te] din la ville éch qu'o n'trouve point din chés piots poéyis.

in the little countries

'They were able to buy in the city what you can't find in these little towns.'

(ii) Ch'étoait gramint des piots ménagers qu'i n'avoait'té [ki.na.vwet.te] point d'auto. it was lot of-the little small farmers that they NEG had not of car

'There were a lot of small farmers who didn't have a car.'

(iii) $\mathrm{Oz}$ avoéme tout no temps pour accouter chés gins qu'i leu dvisoait't [ki.lød.vi.zwet] we had all our time for to-listen the people that they REFL were-chatting 'We had all day to listen to the people who were chatting with each other.'

5. That post-verbal clitics are able to exceed VP syllable structure, suggesting that at least some of the $\sigma$-STRUCTURE constraints are dominated, offers further evidence in favor of a *WEAK-INSTRONG/EMPHATiCSTRESS constraint. Some speakers accept forms such as Dépèq'tt! [depektt] 'Hurry up!', where the [k] could be the coda and the first [t] an appendix, but where there is no position for the second [t]. Similarly, in Donne-mmé [dכ̃nmme] 'Give me', the [n] could be a 
(6) Phrase-initial geminates

a. Ll' as-tu rtrouvèe?

$3 \mathrm{sg}$ AUX you found-fem

'Did you find her?'

b. N'n' êtes-vous bien certain?

of-it are you well certain

'Are you sure about that?'

(7) Phrase-final geminates

a. Non, creuyeu mm'.

No believe $1 \mathrm{sg}$

'No, believe me.'

b. Tais tt'!

shut-up 2sg-REFL

'Shut up!'

When geminates are not in intervocalic position or at the edge of some prosodic boundary - that is, when they occur in a consonantal context where both halves of the geminate cannot be licensed due to a shortage of available positions- one of two courses of action is available: either the geminate shortens, as in (8a), or an epenthetic vowel is inserted, thereby rescuing the intervocalic context so that the geminate can surface faithfully as a long segment, as in (8b). Thus, we see that with respect to syllabification, geminates pattern much like consonant clusters. How they differ is that clusters are not readily simplified (except under very specific circumstances (e.g., /øtr/ $\rightarrow[\varnothing t])$ ) but geminates are fairly readily shortened when available positions are lacking.

(8) Geminates in a consonantal context

a. O l' saveu.

you 3sg know

'You know it.'

b. O llé saveu.

you 3sg know

'You know it.'

coda and the second [m] an onset, but there is no position for the first [m]. In these cases where we get more segments than positions, an emphatic meaning again attaches; these same forms with a singleton - [depekt] and [dõnme]— do not mark any emphasis. 


\subsubsection{Geminates: pronoun-specific observations}

In addition to these general patterns, there are a few pronoun-specific distributional facts that need to be addressed. For instance, pre-verbally, the 1sg and 2sg pronouns occur only as singletons, never geminates, even intervocalically. Examples are provided in (9). The geminate $\sim$ singleton alternations illustrated in (1)-(2), then, are limited to post-verbal position. Conversely, for the 3 sg pronoun, there is no alternation post-verbally: here, we find only geminate [11], never singleton [1]. Examples are provided in (10). For this pronoun, the geminate $\sim$ singleton alternations illustrated in (3) and (8) are limited to pre-verbal position. Likewise, the $[\mathrm{nn}] \sim[\mathrm{n} \tilde{\varepsilon}]$ alternations of the partitive/genitive are restricted to pre-verbal position; as with the $3 \mathrm{sg}$, we find only the geminate allomorph post-verbally. This is shown in (11). Finally, as mentioned in $\S 1$, the $3 \mathrm{pl}$ surfaces only as a geminate regardless of position; the examples in post-verbal position in (12), along with the examples in pre-verbal position in (4), show this.

(9) $1 \mathrm{sg}, 2 \mathrm{sg}$ pre-verbally: singletons only
a. A m' est bien égal.
(*A mm'est)
that $1 \mathrm{sg}$ is well equal
'It's all the same to me.'

b. Tu t' as bérlurè?

you 2sg AUX mistaken

'Did you make a mistake?'

$(*$ Tu tt'as)

(10) 3sg post-verbally: geminate [11] only

a. Dis llé.

(*Dis l')

say 3 sg

'Say it.'

b. Donne é-llé à tin pére.

(*Donne lé) give $3 \mathrm{sg}$ to your father

'Give it to your father.'

(11) Partitive/genitive post-verbally: geminate [nn] only

a. Pis rapporté n-né pour chint sous. (*rapporté nin) and bring-back PART for hundred monetary-unit 'And bring back five franc's worth.'

b. Prindez nné don ène cope éd bouteilles. (*Prindez nin) take PART thus a couple of bottles 'So take a couple of bottles.' 
(12) 3pl post-verbally (also pre-verbally in (4)): geminate [zz]

a. Acouteu zzés jacteu dérriére pour des pronnes. (*Acouteu z’jacteu) listen-to $3 \mathrm{pl}$ to-jabber behind for some prunes 'Listen to them jabbering back there for some prunes.'

b. Mais ouve éz-zés, tes zius! but open them, your eyes

(*ouve zés)

'Open your eyes!'

To summarize, this problem presents us with two main challenges. One is explaining why geminates can occur phrase-initially and phrase-finally in addition to intervocalically, but only where there are two available syllable (or other prosodic) positions. The solution to this follows straightforwardly from geminates consisting of a single feature geometric structure simultaneously linked to two root nodes. The second is explaining why there are alternations where there are but not where there are not, as summarized in table (13). Cells in which there are no alternations are shaded. Given that a grammar, in terms of Optimality Theory, is a fixed, language-specific constraint ranking (abstracting away from various proposals for achieving the variable rankings required to analyze variable phenomena), it seems that this second challenge can be met only by attributing each of the four patterns in table (13) to a different underlying structure. We demonstrate what each of those underlying forms must be and how each is treated by the grammar in $\S 3$.

(13) Positional considerations of (non-)alternations summarized

\begin{tabular}{|l|l|l|}
\hline Pronoun & Pre-verbally & Post-verbally \\
\hline $1 \mathrm{sg}$ & {$[\mathrm{m}]$} & {$[\mathrm{m}] \sim[\mathrm{mm}]$} \\
$2 \mathrm{sg}$ & {$[\mathrm{t}]$} & {$[\mathrm{t}] \sim[\mathrm{tt}]$} \\
\hline $3 \mathrm{sg}$ & {$[\mathrm{l}] \sim[\mathrm{ll}]$} & {$[\mathrm{ll}]$} \\
\hline partitive/genitive & {$[\mathrm{n} \tilde{\varepsilon}] \sim[\mathrm{nn}]$} & {$[\mathrm{nn}]$} \\
\hline $3 \mathrm{pl}$ & {$[\mathrm{zz}]$} & {$[\mathrm{zz}]$} \\
\hline
\end{tabular}

\section{Four patterns analyzed}

In our preceding description of the data, we offered a preview of our analysis. In essence, where two syllable/prosodic positions are available, geminates surface as geminates; where only one syllable/prosodic position is available, either they shorten or a vowel is inserted so that the necessary second syllable position becomes available. The four different patterns depicted in table (13) result from four different underlying structures serving as inputs to the grammar, yielding gemination, geminate maintenance, or degemination. As we will see in the following sections, the $1 \mathrm{sg}$ and $2 \mathrm{sg}$ pronouns are underlying singletons, $/ \mathrm{m}$, t/, which are geminated post-verbally, syllable structure permitting; the 3 sg pronoun is an underlying geminate, /ll/; the partitive/genitive is somewhere in between a singleton and 
a geminate (specifically, we propose that its underlying form is $/ \mathrm{n}^{\mathrm{n}}$, where the superscript «n» represents a floating nasal, following Paradis and El Fenne 1995); and the $3 \mathrm{pl}$ is neither a singleton nor a geminate (specifically, we propose that its underlying form is $/ \mathrm{lz} /$, with $[\mathrm{zz}]$ resulting from full assimilation of the $/ \mathrm{l} /$ to the /z/).

\subsection{The 3 sg pronoun}

We begin our analysis with the only pronoun that is an underlying geminate: the 3 sg accusative clitic. When sufficient syllable/prosodic positions are available, the geminate surfaces faithfully; this is illustrated in the top half of tableau (19), where candidate (c) is selected. When insufficient syllable/prosodic positions are available, as in the bottom half of tableau (19), either the geminate shortens so that it can be accommodated by the lone available position (candidate (h)) or a vowel is inserted so that the entire geminate can be accommodated (candidate (i)). This means that syllable structure requirements, a series of constraints which we abbreviate simply as $\sigma$-STRUCTURE, outrank faithfulness: $\sigma$-STRUCTURE $\gg \operatorname{DEP}(\mathrm{V})$, $\operatorname{MAX}(\mathrm{RoOT})$. These faithfulness constraints, in turn, must outrank the alignment constraint that requires the clitic to occur next to its host; otherwise, candidate (i) would incorrectly be eliminated to the exclusive preference of candidate (h). The basic ranking of $\operatorname{DEP}(\mathrm{V}) » \operatorname{MAX}(\mathrm{ROOT})$-i.e., before the introduction of evaluation-time noise which results in constraints spanning ranges and, consequently, potentially reversing rankings when sufficiently close to each other on the ranking scale (Boersma and Hayes 2001) — follows from degemination being more common than vowel epenthesis. ${ }^{6}$ The double-outlined box in tableau (19) and others is intended to signal this type of «stochastic» relationship between two or more constraints.

(14) $\sigma$-STRUCTURE: An abbreviation for the various constraints responsible for the syllable structure requirements described in $\$ 2.2 .1$; in particular, those that pertain to complex onsets and codas (e.g., SonORITYSEQuencing, etc.).

(15) ONSET: Syllables must have onsets.

(16) $\operatorname{Dep}(\mathrm{V})$ : Every vowel present in the output has a correspondent in the input.

(17) $\operatorname{MAx}($ Root): Every root node present in the input has a correspondent in the output.

(18) Align(Clitic, Verb): Align the right edge of a pronominal clitic with the left edge of the verb (cf. Bonet and Lloret 2005).

6. In a 396-token mini-corpus of /11/ in phrase-internal, pre-verbal position, we observe $68 \%$ degemination (270 tokens) and 32\% vowel epenthesis (126 tokens). 
(19) Pre-verbal geminates: faithful between vowels, variation next to a consonant

\begin{tabular}{|c|c|c|c|c|c|}
\hline $\begin{array}{l}\text { o ll'avoéme } \\
\text { 'we had it' } \\
\text { /o ll avwem/ }\end{array}$ & $\sigma$-STRUCT & ONSET & $\begin{array}{l}\text { DEP } \\
(V)\end{array}$ & $\begin{array}{c}\text { MAX } \\
\text { (RoOT) }\end{array}$ & $\begin{array}{c}\text { Align } \\
\text { (Clitic, Verb) }\end{array}$ \\
\hline a. [oll.a.vwẽm] & $* !$ & [o] [a] & & & [o] \\
\hline b. [o.lla.vwẽm] & $* !$ & [o] & & & [o] \\
\hline 续c. [ol.la.vwẽm] & & [o] & & & [o] \\
\hline d. [o.la.vwẽm] & & {$[0]$} & & $* !$ & [o] \\
\hline e. [ol.le.a.vwẽm] & & [o] [a]! & $*$ & & {$[\mathrm{o}],[11]$} \\
\hline $\begin{array}{l}\text { o l'saveu } \\
\text { o llé saveu } \\
\text { 'you know it' } \\
\text { /o ll savø/ }\end{array}$ & $\sigma$-STRUCT & ONSET & $\begin{array}{l}\text { DEP } \\
(V)\end{array}$ & $\begin{array}{c}\text { MAX } \\
\text { (RoOT) }\end{array}$ & $\begin{array}{c}\text { Align } \\
\text { (Clitic, Verb) }\end{array}$ \\
\hline f. [oll.sa.vø] & $* !$ & [o] & & & [o] \\
\hline g. [ol.lsa.vø] & $* !$ & [o] & & & [o] \\
\hline$\leftrightarrow \mathrm{h}$. [ol.sa.vø] & & [o] & & $* !$ & [o] \\
\hline i. [ol.le.sa.vø] & & [o] & $* !$ & & [o], [11] \\
\hline
\end{tabular}

According to tableau (19), we should expect geminates in initial position before a consonant to shorten due to insufficient positions and geminates in initial position before a vowel to be maintained due to adequate (e.g., appendix + onset) positions. And this is indeed what we find. Observe in the top half of tableau (24) that we do not get an epenthetic vowel between the clitic and the verb pre-consonantally (e.g., candidates (f), $(\mathrm{g})$ ), which would allow the geminate to be maintained before a consonant. Since the clitic and the verb can be separated by an epenthetic vowel in tableau (19) (o llé saveu), but not in tableau (24) (*llé sais-tu), we posit a position-specific version of Align(Clitic, Verb) in (20): Align(InitialClitic, Verb). ${ }^{7}$ In the top half of tableau (24), candidates (a), (b), and (c) are eliminated for violating syllable structure requirements as they pertain to complex onsets and codas, and candidates (f) and (g) because their sole pre-verbal clitics in initial position are not aligned with the verb, in violation of our «positional alignment» constraint. This leaves candidates (d) and (e), with their shortened geminates; either of these may be optimal depending upon the particular rankings of ONSET, *INITIAL-APPENDIX, and $*$ CROSS-SYLLABIFICATION with respect to each other at evaluation time.

Note here that co-optimal candidate (d) actually represents two candidates: in one of these, [1] is licensed as an appendix (and thus violates *INITIAL-APPENDIX); in the other, [1] is cross-syllabified as the coda of a preceding phrase-final open

7. As all of the candidates in tableau (19) (and anywhere else where there is more than one pre-verbal clitic) would violate ALign(InITIALCLITIC, Verb), this constraint would have no decision-making power there. 
syllable (and thus violates *CROSS-SYLLABIFICATION). When *INITIAL-APPENDIX » *Cross-Syllabification, the candidate with an initial appendix is eliminated, and when *CROSS-SYllabIFICATION $» *$ INITIAL-APPENDIX, the candidate with a crosssyllabified coda [1] is eliminated. Of course, if the preceding phrase-final syllable is closed (or if there is not one), cross-syllabification is not an option and we would necessarily get an initial appendix (or an epenthetic vowel in candidate (e)).

Another issue with respect to initial geminates is that our analysis, as developed to this point, incorrectly predicts shortening phrase-initially even before a vowel. This is because, as discussed in conjunction with tableau (19), the constraint against geminate shortening, MAX(RoOT), is normally outranked by $\operatorname{DEP}(\mathrm{V})$; therefore, it, like $\operatorname{DEP}(\mathrm{V})$, must be outranked by the series of constraints responsible for whether initial clusters are syllabified with or without the help of an epenthetic

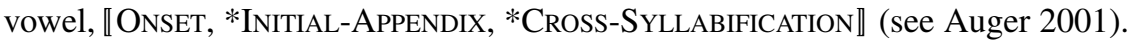
As a result, we predict all geminates in initial position to shorten as (24d, e): it should always be better to violate low-ranking MAX(RoOT) than higher-ranking

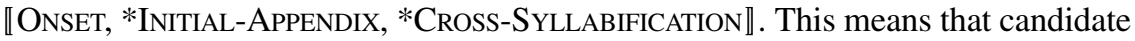
(k) in the bottom half of tableau (24) should be optimal instead of the attested candidates (i) and (j).

We attribute the lack of degemination here to the positional faithfulness constraint in (21): MAX(ROOT)/PHRASE-INITIAL. Beckman (1999: 3) contends that "privileged positions $[\ldots]$ are those positions which enjoy some perceptual advantage in the processing system, via either psycholinguistic or phonetic prominence". While the phrase-initial position is not one that she specifically mentions as being privileged (although root-initial position is), it is certainly consistent with her claim that "positions which are psycholinguistically prominent are those which bear the heaviest burden of lexical storage, lexical access and retrieval, and processing" (Beckman 1999: 3) and Clements' (2003) observation that "salience effects of phrase-initial position [...] most likely [have] a cognitive basis". Although the clitic in candidate (k) can be syllabified as a simple onset, by virtue of being shortened, this results in a fatal violation of the positional faithfulness constraint. Candidate (h) avoids this positional faithfulness violation, but is eliminated for syllabifying the entire geminate as a complex onset, in violation of the relevant $\sigma$-STRUCTURE constraint. Candidates (l) and (m) are eliminated for violating the earlier-introduced positional alignment constraint. This leaves candidates (i) and (j), either of which may be optimal depending upon the particular rankings of ONSET, *INITIALAPPENDIX, and *CROSS-SYLLABIFICATION with respect to each other at evaluation time.

As with candidate (d), co-optimal candidate (i) represents two distinct candidates (as do candidates (b), (f), and (l)): in one of these, the first half of the geminate is licensed as an appendix and in the other it is cross-syllabified as the coda of a preceding phrase-final open syllable. As above, if the preceding phrase-final syllable is closed (or if there is not one), cross-syllabification is not an option and we would necessarily get either an initial appendix in candidate (i) or an epenthetic vowel in candidate $(\mathrm{j})$. 
(20) Align(InitialClitic, Verb): Align the right edge of the initial clitic with the left edge of the verb.

(21) $\operatorname{MAx}($ RoOT)/Phrase-Initial: For a clitic which is the initial morpheme of an Utt or IntPhr, every root node present in the input should have a correspondent in the output.

(22) *Initial-ApPEndix: No initial appendices.

(23) *Cross-SyllabifiCATION: An abbreviation for the alignment constraints that militate against mismatching prosodic and word boundaries (cf. Auger 2001).

(24) Phrase-initial geminates: shorten before a consonant, faithful before a vowel

\begin{tabular}{|c|c|c|c|c|c|c|c|}
\hline $\begin{array}{l}\text { L'sais-tu } \\
\text { Él'sais-tu } \\
\text { 'Do you know it?' } \\
\text { /ll se ty/ }\end{array}$ & 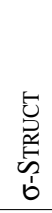 & 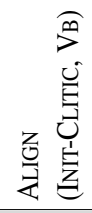 & 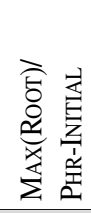 & $\begin{array}{l}\text { 岧 } \\
\text { ż }\end{array}$ & 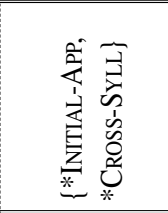 & 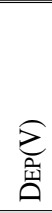 & $\begin{array}{l}\widehat{E} \\
\stackrel{x}{\Sigma} \\
\text { L }\end{array}$ \\
\hline a. [llse.ty] & $* !$ & & & & & & \\
\hline b. [1.1se.ty] & $* !$ & & & & $\begin{array}{l}\left\{{ }^{*} \text { Init-App }\right. \\
{ }^{*} \text { Cross-Syll }\end{array}$ & & \\
\hline c. [ell.se.ty] & $* !$ & & & * & & * & \\
\hline d. [l.se.ty] & & & * & & $\begin{array}{c}\left\{{ }^{*} \text { Init-App, }\right. \\
\left.{ }^{*} \text { Cross-Syll }\right\} !\end{array}$ & & $*$ \\
\hline e. [el.sc.ty] & & & * & $* !$ & & * & * \\
\hline f. [l.le.sc.ty] & & $* !$ & & & $\begin{array}{l}\left\{{ }^{*} \text { Init-App }\right. \\
\left.{ }^{*} \text { Cross-Syll }\right\}\end{array}$ & * & \\
\hline g. [el.le.sc.ty] & & $* !$ & & * & & $* *$ & \\
\hline $\begin{array}{l}\text { Ll'as-tu rtrouvèe } \\
\text { Éll as-tu rtrouvèe } \\
\text { 'Did you find it?' } \\
\text { /ll a ty rtruve/ }\end{array}$ & 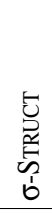 & 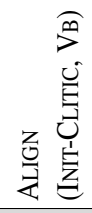 & 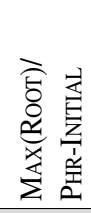 & 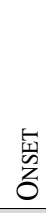 & 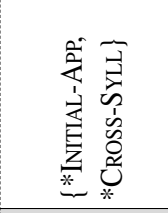 & $\begin{array}{l}\sum_{\text {î }} \\
\text { 今 }\end{array}$ & $\begin{array}{l}\widehat{E} \\
\stackrel{x}{\Sigma} \\
\underline{\Sigma}\end{array}$ \\
\hline h. [lla.ty] & $* !$ & & & & & & \\
\hline \&i. [l.la.ty] & & & & & $\begin{array}{c}\left\{{ }^{*} \text { Init-App, }\right. \\
\left.{ }^{*} \text { Cross-Syll }\right\} !\end{array}$ & & \\
\hline$\because$ j. [el.la.ty] & & & & $* !$ & & $*$ & \\
\hline k. [la.ty] & & & $* !$ & & & & $*$ \\
\hline 1. [1.le.a.ty] & & $* !$ & & * & $\begin{array}{c}\left\{{ }^{*} \text { Init-App }\right. \\
\left.{ }^{*} \text { Cross-Syll }\right\}\end{array}$ & $*$ & \\
\hline m. [el.le.a.ty] & & $* !$ & & ** & & $* *$ & \\
\hline
\end{tabular}


At this point, we take momentary leave of our discussion of the $3 \mathrm{sg}$ pronoun. We will come back to it and discuss the treatment of post-verbal geminates after we look at what happens to the $1 \mathrm{sg}$ and 2 sg pronouns post-verbally.

\subsection{The $1 \mathrm{sg}$ and $2 \mathrm{sg}$ pronouns}

The 1sg and 2sg pronouns are underlying singletons. This explains their lack of alternations pre-verbally: these pronouns surface faithfully in this context, even intervocalically - the position par excellence for geminates- because there is nothing forcing the DEP(RoOT) violation that would be required in order to find geminates here. Post-verbally, on the other hand, a general process of lengthening applies. This results in $/ \mathrm{m} /$ and $/ \mathrm{t} / \mathrm{surfacing}$ as [mm] and [tt], in violation of DEP(RoOT), but only where two syllable positions are available; otherwise, the lengthening is blocked.

A couple of common causes of synchronic lengthening, either of which could be responsible for this process of post-verbal lengthening, are stress-induced lengthening (e.g., STRESS-TO-WEIGHT) and final lengthening. Regardless of which of these is more likely implicated in the case at hand, we might expect that the effect should show up on the syllable nucleus and not on a consonantal clitic. However, final lengthening has been observed to affect not only vowels but also consonants. For example, Berkovits finds that in Hebrew utterance-final lengthening affects final stops (Berkovits 1993a) and fricatives (Berkovits 1993b) proportionally more than the preceding syllable nuclei. She also reports that BellBerti et al. (1991) similarly found final stop closures in monosyllabic nonsense words in French to be "lengthened more than three times as much as the vowel" (Berkovits 1993b: 89) and that numerous other studies have obtained similar findings.

Here, without any particularly compelling reason to choose one of these possible causes of consonant lengthening over the other, we assume that post-verbal lengthening in VP is stress-induced. ${ }^{8}$ This is certainly consistent with attested effects of stress on clitic pronouns in other Romance languages: e.g., me, te $\rightarrow$ moi, toi in French; /cónta+mə+lə/ $\rightarrow$ [cóntammíllə] 'tell it to me' in Neapolitan, /rá+mə+lə/ $\rightarrow$ [rámmíllə] 'give it to me' in Lucanian (Peperkamp 1995). The utility of assuming stress-induced lengthening over final lengthening is that stressed positions are more widely recognized as privileged positions than are final positions (though Clements 2003, 2004 argues that final position is indeed a privileged position, albeit less so than initial position). We posit that the markedness constraint in (26), *WEAK-IN-STRONG, is responsible for this stressed lengthening of post-verbal clitics. Tableau (30) illustrates this stressed lengthening where syllable structure permits it, and its absence where syllable structure blocks it.

8. Stuart Davis (p.c.) suggests an alternate possibility. Consistent with his numerous analyses of geminates as moraic (e.g., Davis 2003), he posits that post-verbal constructions introduce a floating mora which may or may not be realized depending upon syllable structure requirements. 
(25) Align(Verb, Clitic): Align the left edge of a pronominal clitic with the right edge of an affirmative imperative verb (cf. Bonet and Lloret 2005). ${ }^{9}$

(26) *WeAK-IN-Strong: Prosodically weak elements (i.e. singleton clitics) are not permitted in prosodically strong positions (i.e. stressed syllables). ${ }^{10}$

\section{*FINAL-APPENDIX: No final appendices.}

(28) Dep(V)/STRESS: Every vowel in stressed position in the output has a correspondent in the input (do not insert vowels into stressed syllables; i.e., epenthetic vowels are not stressed).

(29) Dep(Root): Every root node present in the output has a correspondent in the input.

In the top half of tableau (30), all of the candidates that fail to lengthen the post-verbal clitic (candidates (a)-(d)) are eliminated. This leaves only those candidates with a «strong» clitic in this strong position; the two of these that separate the clitic and verb (candidates $(\mathrm{g})$ and $(\mathrm{h})$ ) violate the relevant alignment constraint and are eliminated for it. Consequently, candidates (e) and (f) are optimal, depending upon whether *FINAL-APPENDIX dominates DEP(V)/STRESS or whether DeP(V)/STRESS dominates *FINAL-APPENDIX at any given evaluation. ${ }^{11}$ In the bottom half of tableau (30), on the other hand, the weak clitic cannot be lengthened to a strong clitic without either violating syllable structure requirements (candidates (m)-(o)) or separating the clitic from the verb (candidate (p)); therefore, the weak clitic surfaces in this strong position in spite of the markedness constraint *WEAK-IN-STRONG. Of the candidates with a weak clitic, candidate (i) has a final appendix which is not a voiceless stop, which, for the sake of simplicity, we count here as a $\sigma$-STRUCTURE violation; candidates (k) and (l) separate the clitic from its

9. To make sure that a sole object pronoun surfaces as an enclitic after an affirmative imperative verb, satisfying Align(Verb, Clitic) but not Align(InitialClitic, Verb), introduced earlier, Align(Verb, Clitic) must be ranked above Align(InITIALCLITIC, Verb).

10. In assessing *WEAK-IN-STRONG violations, we ask, first, whether a post-verbal clitic is a singleton or a geminate (thus, in the case of the $[\mathrm{nn}] \sim[\mathrm{n} \tilde{\varepsilon}]$ alternations of the partitive/genitive this constraint has no relevance; both (42a, c) and (42e) satisfy it). If a geminate, it necessarily satisfies this constraint; if a singleton, it violates this constraint only if it is syllabified in the stressed syllable. Therefore, in tableaux (30) and (32), but no others, stress, which is final in VP, is shown. In tableau (30), rather than showing syllable boundaries as we do in all of the other tableaux, we put a space between the verb and the clitic so that the possible combinations of lengthening, or the lack thereof, and vowel epenthesis can be seen clearly.

11. Although we show $\llbracket *$ Fin-APP, DeP(V)/STRESS $\rrbracket \llbracket$ ONSET, *INIT-APP, *Cross-SyLL $\rrbracket$, we are unable to determine the ranking of these two subhierarchies with respect to each other based upon the data examined in this paper. Consequently, it may be possible for *INIT-APP and *FIN-APP to be collapsed successfully into a single anti-appendix constraint, *APPENDIX. However, we are hesitant to attempt such a move because initial and final appendices are licensed by different levels of the prosodic hierarchy $(\$ 2.2 .1)$. 
host, in violation of the applicable alignment constraint. Therefore, candidate (j) is optimal.

(30) Post-verbal singletons: lengthen unless blocked by syllable structure

\begin{tabular}{|c|c|c|c|c|c|c|c|c|}
\hline $\begin{array}{l}\text { Tais } t t \text { '! } \\
\text { 'Shut up!' } \\
\text { /te t/ }\end{array}$ & 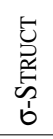 & 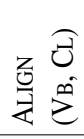 & 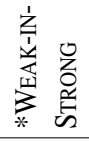 & 窐 & 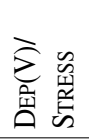 & 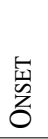 & 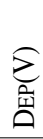 & 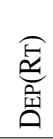 \\
\hline a. [té t] & & & $* !$ & & & & & \\
\hline b. [te té] & & & *! & & $*$ & & $*$ & $*$ \\
\hline c. [te ét] & & $* !$ & $*$ & & $*$ & $*$ & $*$ & $*$ \\
\hline d. [te eté] & & $* !$ & $*$ & & $*$ & $*$ & $* *$ & $* *$ \\
\hline$\leftrightarrow \mathrm{e}$ [tétt] & & & & $* !$ & & & & $*$ \\
\hline$f$ [te tté] & & & & & $* !$ & & $*$ & $* *$ \\
\hline g. [te étt] & & $* !$ & & $*$ & $*$ & $*$ & $*$ & $* *$ \\
\hline h. [tع etté] & & $* !$ & & & $*$ & $*$ & $* *$ & $* * *$ \\
\hline $\begin{array}{l}\text { Acoute mé } \\
\text { 'Listen to me' } \\
\text { /akut m/ }\end{array}$ & 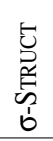 & 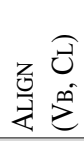 & 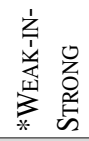 & 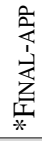 & 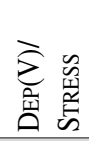 & $\begin{array}{l}\sqrt{5} \\
\text { 号 } \\
0\end{array}$ & 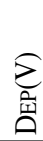 & 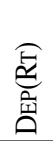 \\
\hline i. [akút m] & $* !$ & & & * & & $*$ & & \\
\hline j. [akut mé] & & & $*$ & & $*$ & * & $*$ & $*$ \\
\hline k. [akut ếm] & & $* !$ & $*$ & & $*$ & * & $*$ & $*$ \\
\hline 1. [akut ẽmé] & & $* !$ & $*$ & & $*$ & $*$ & $* *$ & $* *$ \\
\hline m. [akút mm] & $* ! *$ & & & $*$ & & $*$ & & $*$ \\
\hline n. [akut mmé] & $* !$ & & & & $*$ & $*$ & $*$ & $* *$ \\
\hline o. [akut ếmm] & $* !$ & $*$ & & $*$ & $*$ & $*$ & $*$ & $* *$ \\
\hline p. [akut ẽmmé] & & $* !$ & & & $*$ & * & $* *$ & $* * *$ \\
\hline
\end{tabular}

Now that we have seen that something special happens to post-verbal clitics, we can return to the case of the $3 \mathrm{sg}$ and illustrate the final remaining aspect of that pronoun: its lack of alternations in this position. 


\subsection{The 3 sg pronoun, continued}

Recall that the $3 \mathrm{sg}$ pronoun exhibits alternations pre-verbally but not post-verbally. Post-verbally, /l1/ never shortens. We might suspect this to be related to the process of post-verbal lengthening discussed in $\$ 3.2$, but since /11/ is already long, post-verbal lengthening has no effect. Nonetheless, there is an indirect connection between post-verbal lengthening and the lack of post-verbal degemination with the 3sg pronoun: they are both due to the same driving force, stress. Since /ll/ is underlyingly long, it, unlike $/ \mathrm{m} /$ and $/ \mathrm{t} /$, is subject to a faithfulness constraint that specifically prevents it from shortening in this privileged position even when there are insufficient syllable positions to accommodate it. This results in obligatory vowel epenthesis where degemination would otherwise be a possibility. In this case, /ll/ is not shortened post-verbally after a consonant (compare the lack of $/ \mathrm{m} /$ and $/ \mathrm{t} /$ lengthening after a consonant); instead, an epenthetic vowel is inserted between the verb and the clitic. This means that our new positional faithfulness constraint outranks Align(VERB, Clitic), which, itself, outranks the markedness constraint *WEAK-IN-STRONG, as established in tableau (30).

Because this positional faithfulness constraint, $\operatorname{MAX}(\mathrm{RoOT}) / \mathrm{STRESS}$ in (31), and the various constraints responsible for syllable wellformedness, $\sigma$-STRUCT, outrank Align(VERB, Clitic), all candidates except for the optimal [war.del.lé] (candidate (d)) are immediately eliminated in the top half of tableau (32). Here, then, we see two unusual results: the clitic can be separated from the verb if necessary and an epenthetic vowel can appear in Utt-final position. Turning to the vocalic environment in the bottom half of tableau (32), we get the same result except that the clitic need not be separated from the verb by an epenthetic vowel. It is important to compare the optimal candidate here, candidate $(\mathrm{k})$, with another very plausible candidate, candidate (i). We get an epenthetic vowel in Utt-final position, which is forbidden except with post-verbal clitics, because [1] is not a possible final appendix; in evaluating candidate (i) (also candidates (a), (b), (e), and (j)), we continue to count this as a $\sigma$-STRUCTURE violation, as we did for $[\mathrm{m}]$ in tableau (30).

(31) $\operatorname{MAx}($ RoOT)/STRESS: For a clitic in stressed (i.e. post-verbal) position, every root node present in the input should have a correspondent in the output (do not delete root nodes from clitics in stressed syllables). 
(32) Post-verbal geminates: obligatorily maintained

\begin{tabular}{|c|c|c|c|c|c|c|c|c|c|}
\hline $\begin{array}{l}\text { Warde é-llé! } \\
\text { 'Keep it!' } \\
\text { /ward ll/ }\end{array}$ & 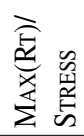 & 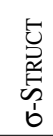 & 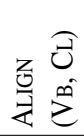 & 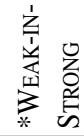 & 育 & 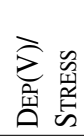 & 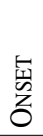 & $\begin{array}{l}\sum_{\text {II }}^{8} \\
\text { ث. }\end{array}$ & 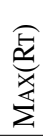 \\
\hline a. [wárdl.1] & & $* ! *$ & & & $*$ & & & & \\
\hline b. [war.dél.1] & & $* !$ & $*$ & & $*$ & $*$ & & $*$ & \\
\hline c. [ward.llé] & & $* !$ & & & & $*$ & & $*$ & \\
\hline d. [war.del.lé] & & & $*$ & & & $*$ & & $* *$ & \\
\hline e. [wárd.1] & & $* !$ & & & $*$ & & & & $*$ \\
\hline f. [war.dél] & $* !$ & & $*$ & $*$ & & $*$ & & $*$ & $*$ \\
\hline g. [ward.lé] & $* !$ & & & $*$ & & $*$ & & $*$ & $*$ \\
\hline h. [war.de.lé] & $* !$ & & $*$ & $*$ & & $*$ & & $* *$ & $*$ \\
\hline $\begin{array}{l}\text { Disons l'lé } \\
\text { 'Let's say it' } \\
/ \operatorname{dizs}^{\mathrm{n}} 1 \mathrm{l} /\end{array}$ & 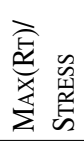 & 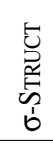 & 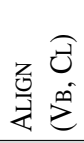 & 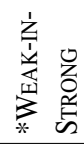 & 蕉 & 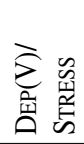 & $\begin{array}{l}\text { 车 } \\
\text { 号 }\end{array}$ & 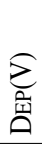 & 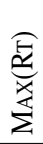 \\
\hline i. [di.zól.l] & & $* !$ & & & $*$ & & & & \\
\hline j. [di.zõ.él.1] & & $* !$ & $*$ & & $*$ & $*$ & $*$ & $*$ & \\
\hline k. [di.zõl.lé] & & & & & & $*$ & & $*$ & \\
\hline 1. [di.zõ.el.lé] & & & $* !$ & & & $*$ & $*$ & $* *$ & \\
\hline m. [di.zól] & $* !$ & & & $*$ & & & & & $*$ \\
\hline n. [di.zõ.él] & $* !$ & & $*$ & $*$ & & $*$ & $*$ & $*$ & $*$ \\
\hline o. [di.z̃̃.lé] & $* !$ & & & $*$ & & $*$ & & $*$ & $*$ \\
\hline p. [di.zõ.e.lé] & $* !$ & & $*$ & $*$ & & $*$ & $*$ & $* *$ & $*$ \\
\hline
\end{tabular}

This concludes our analysis of the basic pattern, as illustrated through the singular pronouns; we turn next to the other two clitic pronouns which have a geminate-consonant allomorph: the $3 \mathrm{pl}$ and the partitive/genitive.

\subsection{The 3pl pronoun}

The 3 pl pronoun consistently surfaces as a geminate. Even where only one syllable/prosodic position is available, no shortening is observed. Instead, vowel epenthesis is obligatory in such contexts. The reason for this follows from the underlying form of this pronoun. The $3 \mathrm{pl}$ pronoun is actually bimorphemic, consisting of a 3rd person morpheme and a plural morpheme, both of which must be realized, following Kurisu (2001). Specifically, the underlying form of this pronoun is /lz/, with the 3rd person morpheme /1/ assimilating to the plural morpheme /z/. There is 
ample cross-Romance evidence supporting /lz/, including data from numerous dialects of Picard (cf. Dauby 1979: 33 and Mahieu 1984: 63 for Picard; Bonet and Lloret 2005: 47 for Catalan). Additionally, we know that many /l/-final clitics undergo assimilation and gemination in certain varieties of Picard, including VP (Cardoso 2001; Flutre 1977: 156-157; Morin 1995). If [zz] were to shorten in a consonantal environment, either the 3rd person morpheme or the plural morpheme would fail to be realized, so vowel epenthesis becomes obligatory in such contexts. Tableau (36) demonstrates.

(33) Assim $/ \mathrm{lz} / \rightarrow$ [zz]: An abbreviation for the constraints responsible for categorical /l/ assimilation in the specific context of the $3 \mathrm{pl}$ pronoun.

(34) ReAlizeMorPHEME: Every underlying morpheme must receive some phonological exponence (Kurisu 2001).

(35) /1/-FAITH: An abbreviation for the constraints that militate against /1/ assimilation.

(36) $3 \mathrm{pl} / \mathrm{lz} /$ : assimilates to [zz] and surfaces «faithfully»

\begin{tabular}{|c|c|c|c|c|c|}
\hline $\begin{array}{l}\text { a zz'éroait acatès } \\
\text { 'she would've bought them' } \\
\text { /a lz erwe akate/ }\end{array}$ & $\begin{array}{c}\text { Assim } \\
/ \mathrm{lz} / \rightarrow[\mathrm{zz}]\end{array}$ & $\begin{array}{c}\text { REALIZE } \\
\text { MORPHEME }\end{array}$ & $\begin{array}{c}\sigma- \\
\text { STRUCT }\end{array}$ & $\begin{array}{c}/ 1 /- \\
\text { FAITH }\end{array}$ & $\begin{array}{l}\text { DEP } \\
(V)\end{array}$ \\
\hline a. [al.zer.we...] & $* !$ & & & & \\
\hline b. [a.zer.we...] & & $* !$ & & & \\
\hline c. [az.zer.we...] & & & & $*$ & \\
\hline $\begin{array}{l}\text { acouteu zzés jacteu } \\
\text { 'listen to them jabber' } \\
\text { /akutø lz zaktø/ }\end{array}$ & $\begin{array}{c}\text { Assim } \\
/ \mathrm{lz} / \rightarrow[\mathrm{zz}]\end{array}$ & $\begin{array}{c}\text { REALIZE } \\
\text { MORPHEME }\end{array}$ & $\begin{array}{c}\sigma- \\
\text { STRUCT }\end{array}$ & $\begin{array}{c}/ 1 /- \\
\text { FAITH }\end{array}$ & $\begin{array}{l}\text { DEP } \\
(\mathrm{V})\end{array}$ \\
\hline d. [a.ku.tøl.zzak.tø] & $* !$ & & $*$ & & \\
\hline e. [a.ku.tøl.ze.zak.tø] & $* !$ & & & & * \\
\hline f. [a.ku.tøz.zzak.tø] & & & $* !$ & $*$ & \\
\hline g. [a.ku.tøz.zak.tø] & & $* !$ & & & \\
\hline h. [a.ku.tøz.ze.zak.tø] & & & & $*$ & * \\
\hline
\end{tabular}

In tableau (36), we see that /lz/ must surface as [zz], otherwise one of the highranking constraints Assim $/ \mathrm{lz} / \rightarrow$ [zz] or REALIZEMORPHEME is violated. Between vowels (top half of tableau (36)), we get [zz] straightforwardly; next to a consonant (bottom half of tableau (36)), the elimination of (36f) to the preference of (36h) shows that the ranking $\sigma$-STRUCT $\gg \operatorname{DEP}(\mathrm{V})$ yields vowel epenthesis where needed. We turn now to our final pronoun: the partitive/genitive. 


\subsection{The partitive/genitive pronoun}

As with the $3 \mathrm{pl}$, the idiosyncratic nature of the partitive/genitive pronoun is due to its underlying form. Here, the idiosyncrasy is more the particular alternation observed - $[\mathrm{nn}] \sim[\mathrm{n} \tilde{\varepsilon}]$ as opposed to $[\mathrm{nn}] \sim[\mathrm{n}]$ — than the lack of alternations post-verbally, although we must also account for this latter issue. We propose that the underlying form of this pronoun is $/ \mathrm{n}^{\mathrm{n}}$, where, again, the superscript «n» represents a floating nasal (Paradis and El Fenne 1995). Following Zoll (1998), we assume that the difference between a floating segment and an anchored segment is that the former is unassociated to any root node in the input while the latter is linked to a root node. Before a vowel-initial word (e.g., J'énn'ai foait in (5a)), the sequence $/ \mathrm{n}^{\mathrm{n}} \mathrm{V}$ / is very normally syllabified as [n.nV] (although an epenthetic vowel may be required to introduce the coda position for the first, i.e. the anchored, [n]). Before a consonant-initial word, on the other hand (e.g., a nin rioait in $(5 \mathrm{~b})$ ), the sequence $/ \mathrm{n}^{\mathrm{n}} \mathrm{C} /$ cannot be syllabified without the insertion of an epenthetic vowel; the floating

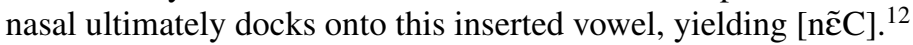

Before we delve any further into the discussion of this clitic, we should first note that there are two types of nasal vowels in VP (Vasseur 1998). In one of these, the nasal feature is primarily linked to the vowel itself (these are what Vasseur 1998 calls the «nasal» vowels); in the other, the nasal feature is primarily linked to a neighboring consonant and is associated to the vowel only by regressive spreading (these are what Vasseur 1998 calls the «half-nasal» —a.k.a. nasalized— vowels). (For discussion, see José and Auger 2004: §§2.2, 4.1.) Of particular relevance here is that in the

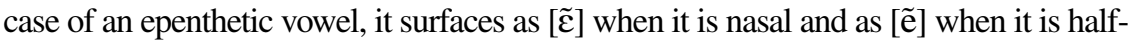
nasal. (Indeed, the same is true of underlying /e/.) Both half-nasal and nasal vowels occur in the candidates in the following tableaux (e.g., (38d) vs (38e), (38i) vs. (38j)).

12. An anonymous reviewer indicates that (s)he finds the UR we posit for this clitic surprising. Pointing out that sequences of adjacent identical segments within a single morpheme are normally analyzed as sharing a common feature structure (i.e., the representation of geminates that we assume here), the reviewer is understandably skeptical of a normal-nasal-plus-rootless-(but-otherwise-identical)floating-nasal sequence. Frankly, we, too, were initially leery of this input; but we are now confident that this is the UR of this clitic. The principal reason for this is that $/ \mathrm{n}^{\mathrm{n}} /$ accounts for the distribution of allomorphs, whereas other URs that we might consider $-/ \mathrm{nn} /, / \mathrm{n} /, / \mathrm{n} \varepsilon \mathrm{n} /$, and $/ \mathrm{n} \varepsilon^{\mathrm{n}} /$ - are unable to. Also, the partitive/genitive pronoun is not the only one that patterns in this way. The mas-

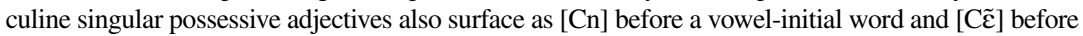

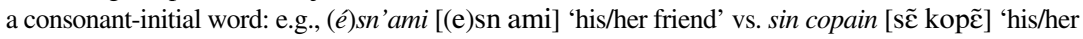
friend'. Thus, we posit the same type of structure for these as we do for the partitive/genitive: $/ \mathrm{m}^{\mathrm{n}}$, $/ \mathrm{t}^{\mathrm{n}} /$, and $/ \mathrm{s}^{\mathrm{n}} /$. And in the absence of morpheme structure constraints or some other such restriction on inputs in OT (cf. McCarthy 2003), if we allow / $\mathrm{C}$ /, Richness of the Base (Prince and Smolensky 2004) requires us to allow $/ \mathrm{n}^{\mathrm{n}} /$ as a possible instantiation of $/ \mathrm{C}^{\mathrm{n}} /$, unless $/ \mathrm{n}^{\mathrm{n}} /$ is universally ill-formed rather than ruled out on a language-specific basis. This, though, would require the OCP to be a condition on inputs and not a violable output constraint, as Myers (1997) has convincingly argued that it is. An important caveat here is that Myers focuses on OCP violations across morpheme boundaries and not morpheme-internally. All that he says about the OCP within morphemes is that Lexicon Optimization (Prince and Smolensky 2004) will always select an OCP-obeying input over an OCPviolating input (Myers 1997: 889, fn. 31). McCarthy (2005), though, argues that other considerations can sometimes override the predictions of Lexicon Optimization. 
(37) MAX[nasal]: Every occurrence of the feature [nasal] in the input has a correspondent in the output.

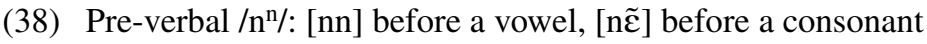

\begin{tabular}{|c|c|c|c|c|c|}
\hline $\begin{array}{l}\text { O no nn'aloéme } \\
\text { 'We were going' } \\
\text { /o no } \mathrm{n}^{\mathrm{n}} \text { alwem/ }\end{array}$ & $\begin{array}{c}\text { MAX } \\
\text { [nasal] }\end{array}$ & $\begin{array}{c}\sigma- \\
\text { STRUCT }\end{array}$ & ONSET & $\begin{array}{l}\text { DEP } \\
(V)\end{array}$ & $\begin{array}{l}\text { DEP } \\
\text { (RT) }\end{array}$ \\
\hline a. [õ.nõn.nal.wẽm] & & & [o] & & $*$ \\
\hline b. [õ.nõ.nal.wẽm] & $* !$ & & [o] & & \\
\hline c. [õ.nõn.ne.al.wẽm] & & & [o] [a]! & $*$ & $* *$ \\
\hline d. [õ.nõ.nẽ.nal.wẽm] & & & [o] & $* !$ & $* *$ \\
\hline e. [õ.nõ.nc̃.al.wẽm] & & & [o] [a]! & * & $*$ \\
\hline $\begin{array}{l}\text { A nin rioait } \\
\text { 'She was laughing about it' } \\
\text { /a } \mathrm{n}^{\mathrm{n}} \text { riwe/ }\end{array}$ & $\begin{array}{c}\text { MAX } \\
\text { [nasal] }\end{array}$ & $\begin{array}{c}\sigma- \\
\text { StRUCT }\end{array}$ & ONSET & $\begin{array}{l}\text { DEP } \\
(\mathrm{V})\end{array}$ & $\begin{array}{l}\text { DEP } \\
(\mathrm{RT})\end{array}$ \\
\hline f. [ãn.nri.we] & & $* !$ & [a] & & $*$ \\
\hline g. [ãn.ri.we] & $* !$ & & [a] & & \\
\hline h. [ãn.ne.ri.we] & & & [a] & $*$ & $* * !$ \\
\hline i. [ã.nẽn.ri.we] & & & [a] & $*$ & $* * !$ \\
\hline 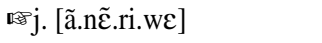 & & & [a] & $*$ & $*$ \\
\hline
\end{tabular}

If we insert a vowel where it is not needed (i.e. before another vowel), we unnecessarily violate faithfulness, potentially creating a superfluous violation of ONSET, eliminating candidates (c), (d), and (e) in the top half of tableau (38). DEP(RоOT) does have to be violated in order for the floating nasal to surface as an onset, but this is better than the alternative: while «shortening» the input, as in candidate (b), does not violate $\operatorname{MAx}($ RoOT), given that the floating nasal is underlyingly rootless, this does require us to delete an input [nasal], in violation of highranking MAX[nasal]. ${ }^{13}$ Therefore, candidate (a) is optimal. ${ }^{14}$ Before a consonant, on

13. For a more extensive discussion of the phonology of [nasal] in VP, including some other consequences of MAX[nasal] and evidence that it is a high-ranking constraint, see José and Auger (2004). Although tableau (38) may give the impression that MAX[nasal] is undominated, this cannot be

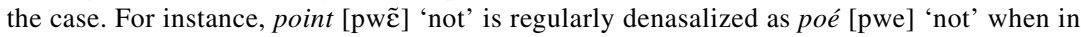
unstressed position: a n'insistouot point [pwẽ] 'she didn't insist' vs. o n-n'oz ons poé [pwe] comprins 'we didn't understand each other'. Also, nasality can be deleted in what is probably a case of haplology: ' $n$ ' and ' $n i n$ ' represent both negative /n/ and the partitive/genitive complement in $a$ nn'avoait point pérlè 'she didn't talk about it' and j'nin sais rién d'plus 'I don't know anything else about it'.

14. Kathryn Tippetts (p.c.) asks why the floating nasal surfaces as an onset before a vowel and not as a nasal feature on that vowel (e.g., /...n $\mathrm{n}^{\mathrm{n}} \mathrm{a} . . / \rightarrow *[\ldots$ nã...]), which would satisfy both MAx[nasal] and $\operatorname{DeP}(\operatorname{RoOT})$. Most often, this can be ruled out by ONSET (e.g., boin 'good' /bwe $/ \rightarrow[$ bwẽ $]$, 
the other hand, if we do not insert a vowel, either a $\sigma$-STRUCTURE violation results (candidate (f)) or we fail to realize the input floating nasal (candidate (g)). Candidate (j) is preferred to candidates (h) and (i) in the bottom half of tableau (38) because candidate (j) violates DEP(ROOT) only once, for the inserted vowel, while candidates (h) and (i) each violate Dep(RoOT) twice, once for the inserted vowel and once for the consonantal root node where the floating [nasal] surfaces.

The lack of post-verbal alternations with this pronoun, where we get only [nn], never [ñ̃], is most certainly related to the process of post-verbal lengthening that we introduced earlier. The different outcomes of vowel epenthesis after this pronoun when it is pre-verbal vs. post-verbal are particularly telling. Pre-verbally, as

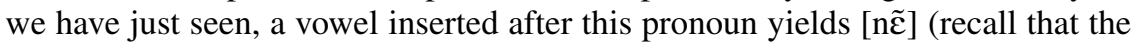
quality of [e] changes to [ $\varepsilon$ ] when it bears the full force of a [nasal] feature); postverbally, a vowel inserted after this pronoun yields [nne]. This, of course, is expected if the addition of a root node has first lengthened $/ \mathrm{n}^{\mathrm{n}} /$ to [nn], just as it has lengthened $/ \mathrm{m} /$ and $/ \mathrm{t} /$ to $[\mathrm{mm}]$ and $[\mathrm{tt}] .{ }^{15}$ Even though we are not dealing here with opacity, of either the non-surface-apparent variety or the non-surface-true variety, we assume that faithfulness to intermediate [nn] is achieved by a high-ranking constraint requiring the output to be faithful to a sympathetic candidate (McCarthy 1999), MAX-ES O(ROOT)/STRESS, but it is possible that the same result could be achieved by means of some other mechanism such as constraint conjunction or strata-specific rankings (see McCarthy 1999: 382-391 for a summary). ${ }^{16}$

Tableau (41) illustrates the selection of the sympathy candidate and tableau (42) the selection of the optimal candidate based upon the sympathy candidate. The selector constraint is $\operatorname{DEP}(\mathrm{V})$, as indicated by the preceding this constraint. In sympathy candidate selection (tableau (41)), only those candidates that satisfy the selector constraint are considered; among these, the candidate that best satisfies

boin + appétit 'enjoy your meal' $=$ [bwẽ.na.pe.ti]; both $*[$ bwẽ.a.pe.ti] and $*[$ bwe.ã.pe.ti] violate ONSET, which outranks DEP(ROOT)). But with $/ \mathrm{C}^{\mathrm{n}} /$, the onset could and should be filled by the $/ \mathrm{C} /$ (e.g., $/ \mathrm{s}^{\mathrm{n}} \mathrm{ami} / \rightarrow$ *[sã.mi]). There must be some other reason, then, that a floating nasal does not dock onto a following vowel. At present, we do not have an explanation, but one possibility is that only leftward nasal linking is permitted. While seemingly convenient, there is some justification for this: pre-N but not post-N vowels are allophonically nasalized in VP. José and Auger (2004) attribute this directionality to markedness $\left({ }^{*}{ }_{\text {[oral] }} \mathrm{V}_{\text {[nasal] }} \mathrm{C} \gg\right.$ DePPATH[nasal]), but if the lack of rightward nasalization is more general, then perhaps it should be attributed, instead, to faithfulness (e.g., NoSpREAD-R[nasal] » * ${ }_{\text {[oral] }} \mathrm{VN}, *^{\mathrm{N} V} \mathrm{C}_{\text {[oral] }}$ » NOSPREAD-L[nasal]).

15. This is not to say that post-verbal [nn] is a geminate in the same sense that [11], [mm], and [tt] are. Geminate [11], [mm], and [tt] are truly geminates in the sense that they consist of a single feature geometric structure doubly-linked to two root nodes. On the other hand, [nn] is not a geminate, properly speaking, in that it has two feature geometric structures, each of which is singly-linked to its two root nodes.

16. This $\mathrm{O}$-faithfulness constraint needs to be specified for stressed position as in (39); otherwise, the wrong candidate emerges as optimal in the bottom half of tableau (38). In (38), candidates (a, f) would be selected as the sympathy candidates, and if this sympathy constraint is simply MAX$\Leftrightarrow \mathrm{O}$ (Root), then the attested candidate (j) would be eliminated for violating it (see footnote 17). Alternatively, it could be that the selector constraint should be DEP(V)/Stress instead of DEP(V), which would yield the correct results in both tableaux (41)/(42) and tableau (38); but the STRESS condition must be included somewhere. 
the (rest of the) constraint hierarchy, minus any sympathy constraints, is selected as the sympathy candidate. Here, this is candidate (a). For the selection of the optimal candidate (tableau (42)), all constraints, including sympathy constraints and the selector constraint, become relevant again. Candidates are evaluated normally, with sympathy constraints - and only sympathy constraints- evaluating correspondence between the sympathy candidate, here candidate (a), and each of the output candidates. In tableau (42) sympathy constraints rule out candidates (b), (d), and (e), leaving candidates (a) and (c). ${ }^{17}$ The former of these, candidate (a), is ruled out for violating syllable structure requirements: the sequence [nn] cannot be licensed in final position ([n] not being a possible final appendix); so, candidate (c), with its final epenthetic vowel, is optimal.

(39) MAX- $s_{9} \mathrm{O}(\mathrm{RoOT}) / \mathrm{STRESS}$ : For a clitic in stressed (i.e. post-verbal) position, every root node in the sympathy candidate has a correspondent in the output (between the sympathy candidate and an output candidate, do not delete root nodes from clitics in stressed syllables).

(40) MorphConTIG- $\varphi_{9}$ O: Segments that form a contiguous string within a morpheme in the sympathy candidate form a contiguous string in that morpheme in the output.

(41) Post-verbal $/ \mathrm{n}^{\mathrm{n}} /$ : sympathy candidate selection

\begin{tabular}{|c|c|c|c|c|c|c|c|c|}
\hline $\begin{array}{l}\text { Prindez nné } \\
\text { 'Take some' } \\
/ \operatorname{pre}^{\mathrm{n}} \mathrm{de}^{\mathrm{n}} /\end{array}$ & 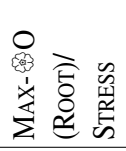 & 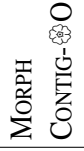 & 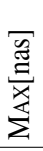 & 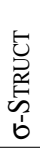 & 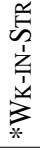 & 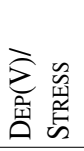 & 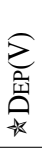 & 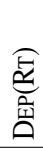 \\
\hline 毁a. [prẽ.dẽn.n] & & & & $*$ & & & & $*$ \\
\hline b. [prẽ.dẽn] & & & *! & & $*$ & & & \\
\hline c. [prẽ.dẽn.ne] & & & & & & $*$ & $* !$ & $* *$ \\
\hline d. [prẽ..dẽn.nẽn] & & & & & & $*$ & $* !$ & ** \\
\hline e. [prẽ.dẽ.ñ̃ ] & & & & & & * & $* !$ & $*$ \\
\hline
\end{tabular}

17. We are assuming that candidate (42e) deletes a consonantal root node present in the sympathy candidate and inserts a vowel, thus its violations of $\operatorname{Dep}(\mathrm{V})$ and $\operatorname{Dep}(\mathrm{RT})$ in addition to MAX$\$ \mathrm{O}$ (RoOT)/STRESS. A homophonous candidate (42e') would turn the sympathy candidate's second consonantal root node into a vocalic root node; such a state of affairs could be ruled out by

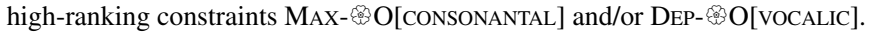


(42) Post-verbal $/ \mathrm{n}^{\mathrm{n}} /$ : optimal candidate selection

\begin{tabular}{|c|c|c|c|c|c|c|c|c|}
\hline $\begin{array}{l}\text { Prindez nné } \\
\text { 'Take some' } \\
/ \text { pre }^{\mathrm{n}} \text { de } \mathrm{n}^{\mathrm{n}} /\end{array}$ & 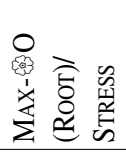 & 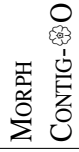 & $\frac{\bar{a}}{\stackrel{\bar{\Xi}}{x}}$ & 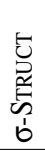 & 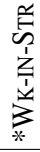 & 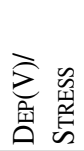 & 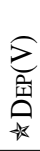 & 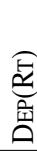 \\
\hline 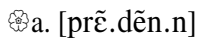 & & & & $* !$ & & & & $*$ \\
\hline b. [prẽ.dẽn] & $* !$ & & $*$ & & $*$ & & & \\
\hline$\leftrightarrow$ c. [prẽ.dẽn.ne] & & & & & & $*$ & $*$ & $* *$ \\
\hline d. [prẽ.dẽ.nẽn] & & $* !$ & & & & $*$ & $*$ & $* *$ \\
\hline e. [prẽ..dẽ.ñ̃ ] & $* !$ & & & & & $*$ & $*$ & $*$ \\
\hline
\end{tabular}

\section{Conclusion}

In this paper, we have shown that the various allomorphs of select pronominal clitics in VP can all be derived by the grammar from a single underlying form per pronoun. We have also seen that four distinct underlying structures must be posited in order to account for the four different patterns observed. The fact that geminates occur only where two syllable or other prosodic positions are available follows from geminates consisting of two identical root nodes. Table (43) summarizes both the underlying forms of the pronouns examined here and our analysis accounting for how they are realized in pre-verbal as well as post-verbal positions. That analysis relies, in part, on applying Sympathy Theory where there is no opacity, on extending positional faithfulness constraints from IO-correspondence to $\$ s^{3} \mathrm{O}$-correspondence, on and extending positional stipulations from faithfulness and markedness constraints to alignment constraints. (However, taking alignment constraints to be a type of markedness constraint, this final device does not constitute much of an extension of the theory.) Finally, the investigation that we have conducted here requires us to modify, ever so slightly, some of the underlying forms posited by Auger (2003b). Specifically, she suggests that "Many pronominal clitics consist of a single consonant: / $3 /$ ' $\mathrm{I}$ ', /m/ 'me', /t/ '2sg.non-nom', and /s/ '3sg.refl'. Others consist of geminate consonants: /l1/ '3sg.acc', /nn/ '3sg.gen', and /zz/ '3pl.acc"' (Auger 2003b: 7). It remains true that many pronominal clitics consist of singleton consonants and that others consist of surface geminate consonants, but we have seen here that the underlying forms of the $3 \mathrm{sg}$.gen and the 3 placc must be $/ \mathrm{n}^{\mathrm{n}} /$ and $/ \mathrm{lz} /$, respectively, and not $/ \mathrm{nn} /$ and $/ \mathrm{zz} /$, as posited by Auger (2003b). 
(43) Underlying forms and how they are handled by the grammar

\begin{tabular}{|c|c|c|c|}
\hline Pronoun & UR & Pre-verbally & Post-verbally \\
\hline $1 \mathrm{sg}, 2 \mathrm{sg}$ & $/ \mathrm{m}, \mathrm{t} /$ & faithful & $\begin{array}{l}\text { lengthen to }[\mathrm{mm}] \\
\text { and }[\mathrm{tt}] \text { except where } \\
\text { insufficient prosodic } \\
\text { positions }\end{array}$ \\
\hline $3 \mathrm{sg}$ & $/ 11 /$ & $\begin{array}{l}\text { faithful except } \\
\text { where insufficient } \\
\text { prosodic positions }\end{array}$ & $\begin{array}{l}\text { consistently [11] due } \\
\text { to positional } \\
\text { faithfulness }\end{array}$ \\
\hline $3 \mathrm{pl}$ & $/ \mathrm{lz} /$ & $\begin{array}{l}\text { assimilates to }[\mathrm{zz}] \\
\text { and surfaces } \\
\text { faithfully due to } \\
\text { morpheme realization }\end{array}$ & $\begin{array}{l}\text { assimilates to [zz] } \\
\text { and surfaces faithfully } \\
\text { due to morpheme } \\
\text { realization }\end{array}$ \\
\hline partitive/genitive & $/ \mathrm{n}^{\mathrm{n}} /$ & $\begin{array}{l}\text { before a vowel, } \\
\text { floating [nasal] } \\
\text { becomes onset, } \\
\text { surfacing as [nn]; } \\
\text { before a consonant, } \\
\text { floating [nasal] docks } \\
\text { onto epenthetic } \\
\text { vowel, surfacing } \\
\text { as [ñ̃] }\end{array}$ & $\begin{array}{l}\text { lengthens to [nn] } \\
\text { and surfaces faithfully } \\
\text { due to } \$ \text { O-FAITH }\end{array}$ \\
\hline
\end{tabular}

\section{References}

Auger, Julie (2000). «Phonology, Variation, and Prosodic Structure: Word-Final Epenthesis in Vimeu Picard». In: Fontana, Josep M.; McNally, Louise; Turell, M. Teresa; Vallduví, Enric (eds.). Proceedings of the First International Conference on Language Variation in Europe (ICLaVE 1). Barcelona: Universitat Pompeu Fabra, pp. 14-24.

Auger, Julie (2001). «Phonological Variation and Optimality Theory: Evidence from Word-Initial Vowel Epenthesis in Vimeu Picard». Language Variation and Change 13: 253-303.

Auger, Julie (2002). «Picard Parlé, Picard Écrit: Dans quelle mesure l'écrit représentet-il l'oral?». In: Pusch, Claus; Raible, Wolfgang (eds.). Romanistische Korpuslinguistik: Korpora und gesprochene Sprache. Tübingen: Gunter Narr, pp. 265-278.

Auger, Julie (2003a). «Picard Parlé, Picard Écrit: Comment s'influencent-ils l'un l'autre?». In: Landrecies, Jacques; Petit, Aimé (eds.). Bien Dire et Bien Aprandre $N^{\circ}$ 21: Picard d'hier et d'aujourd'hui. Lille: Centre d'Études Médiévales et Dialectales de Lille 3, pp 17-32.

Auger, Julie (2003b). «Picard Pronominal Clitics Revisited». In: Núñez-Cedeño, Rafael; López, Luis; Cameron, Richard (eds.). A Romance Perspective on Language Knowledge and Use: Selected Papers from the 31st Linguistic Symposium on 
Romance Languages (LSRL), Chicago, 19-22 April 2001. Amsterdam: John Benjamins, pp. 3-20.

Beckman, Jill N. (1999). Positional Faithfulness: An Optimality Theoretic Treatment of Phonological Asymmetries. New York: Garland.

Bell-Berti, Fredericka; Gelfer, Carole; Boyle, Mary; Chevrie-Muller, Claude (1991). «Speech Timing in Ataxic Dysarthia». Proceedings of the 12th International Congress of Phonetic Sciences 5. Aix-en-Provence: Université de Provence, pp. 262-265.

Berkovits, Rochele (1993a). «Utterance-Final Lengthening and the Duration of FinalStop Closures». Journal of Phonetics 21: 479-489.

Berkovits, Rochele (1993b). «Progressive Utterance-Final Lengthening in Syllables with Final Fricatives». Language and Speech 36: 89-98.

Boersma, Paul; Hayes, Bruce (2001). «Empirical Tests of the Gradual Learning Algorithm». Linguistic Inquiry 32: 45-86.

Bonet, Eulàlia; Lloret, Maria-Rosa (2005). «More on Alignment as an Alternative to Domains: The Syllabification of Catalan clitics». Probus 17: 37-78. [Available on Rutgers Optimality Archive \#592, http://roa.rutgers.edu/.]

Broselow, Ellen (1995). «Skeletal Positions and Moras». In: Goldsmith, John A. (ed.). The Handbook of Phonological Theory. Cambridge, MA: Basil Blackwell, pp. 175-205.

Cardoso, Walcir (2001). «Variation Patterns in Across-Word Regressive Assimilation in Picard: An Optimality Theoretic Account». Language Variation and Change 13: 305-341.

Clements, J. Clancy (2003). «Salience Effects of the Phrase-Initial Position: Commonalities of Topic, Subject, Determiner, and Prenominal Adjective Position». Invited lecture at the Hispanic Linguistics Colloquium Series of the Department of Spanish and Portuguese, Ohio State University, 31 January 2003.

Clements, J. Clancy (2004). «"On the Edges": Salience Effects of Edges in Clauses, Phrases, etc.». Paper presented at the Department of Linguistics Colloquium Series, Indiana University, 23 January 2004.

Curtis, Emily (2003). Geminate Weight: Case Studies and Formal Models. University of Washington, doctoral dissertation.

Dauby, Jean (1979). Le Livre du "Rouchi": Parler Picard de Valenciennes. Second edition. Amiens: Musée de Picardie.

Davis, Stuart (2003). «The Controversy over Geminates and Syllable Weight». In: Féry, Caroline; van de Vijver, Ruben (eds.). The Syllable in Optimality Theory. Cambridge: Cambridge University Press, pp. 77-98.

Flutre, Louis-Fernand (1977). Du Moyen Picard au Picard Moderne. Amiens: Musée de Picardie.

Ham, William H. (2001). Phonetic and Phonological Aspects of Geminate Timing. New York: Routledge.

Hayes, Bruce (1989). «Compensatory Lengthening in Moraic Phonology». Linguistic Inquiry 20: 253-306.

José, Brian (forthcoming). «The Prosodic Morphology of (Historical) Hausa Pluractional Verb Reduplication». In: Adams, Nikki; Cooper, Adam; Parrill, Fey; Wier, Thomas (eds.). Papers from the 40th Regional Meeting of the Chicago Linguistic Society, Volume 2: The Panels. Chicago: Chicago Linguistic Society. 
José, Brian; Auger, Julie (2004). «(Final) Nasalization as an Alternative to (Final) Devoicing: The Case of Vimeu Picard». In: José, Brian; de Jong, Kenneth (eds.). IULC Working Papers Online 4. [Available on https://www.indiana.edu/ iulcwp/.] Kraehenmann, Astrid (2003). Quantity and Prosodic Asymmetries in Alemannic: Synchronic and Diachronic Perspectives. Berlin: Mouton de Gruyter.

Kurisu, Kazutaka (2001). The Phonology of Morpheme Realization. University of California, Santa Cruz, doctoral dissertation. [Available on Rutgers Optimality Archive \#490, http://roa.rutgers.edu/.]

Mahieu, Paul (1984). Él' Patois d'ichi et comint qu'in s'in sert: Notes de Grammaire sur le Patois Picard de Tournai et des Environs. Tournai: Maison de la Culture de Tournai.

McCarthy, John J. (1979). Formal Problems in Semitic Phonology and Morphology. Massachusetts Institute of Technology, doctoral dissertation. [Distributed 1982 by Indiana University Linguistics Club.]

McCarthy, John J. (1999). «Sympathy and Phonological Opacity». Phonology 16: 331-399.

McCarthy, John J. (2003). «The Length of Stem-Final Vowels in Colloquial Arabic». University of Massachusetts, Amherst, unpublished manuscript. [Available on Rutgers Optimality Archive \#616, http://roa.rutgers.edu/.]

McCarthy, John J. (2005). «Taking a Free Ride in Morphophonemic Learning». Catalan Journal of Linguistics 4: 19-55.

McCarthy, John J.; Prince, Alan (1986 [1996]). «Prosodic morphology 1986». Report no. RuCCS-TR-32. New Brunswick, NJ: Rutgers University Center for Cognitive Science. [Available at http://ruccs.rutgers.edu/tech_rpt/pm86all.pdf/.]

Morin, Yves Charles. 1995. «La Nature des Contraintes Structurales sur le Changement Phonétique: Dégémination et Gémination en Roman Occidental». In: Koskinen, Päivi (ed.). Proceedings of the 1995 Annual Conference of the Canadian Linguistic Association. Toronto Working Papers in Linguistics, pp. 361-372.

Muller, Jennifer (2002). The Phonology and Phonetics of Word-Initial Geminates. Ohio State University, doctoral dissertation.

Myers, Scott (1997). «OCP Effects in Optimality Theory». Natural Language and Linguistic Theory 15: 847-892.

Paradis, Carole; El Fenne, Fatimazohra (1995). «French Verbal Inflection Revisited: Constraints, Repairs and Floating Consonants». Lingua 95: 169-204.

Peperkamp, Sharon (1995). «Enclitic Stress in Romance». In: Dainora, Audra; Hemphill, Rachel; Luka, Barbara: Need, Barbara; Pargman, Sheri (eds.). Papers from the 31st Regional Meeting of the Chicago Linguistic Society, Volume 2: The Parasession on Clitics. Chicago: Chicago Linguistic Society, pp. 234-249.

Popescu, Alexandra (2000). «The Morphophonology of the Romanian Clitic Sequence». Lingua 110: 773-799.

Prince, Alan S.; Smolensky, Paul (2004). Optimality Theory: Constraint Interaction in Generative Grammar. Oxford \& Malden, MA: Blackwell.

Schmidt, Deborah (1992). «Compensatory Lengthening in a Segmental Moraic Theory of Representation». Linguistics 30: 513-534.

Selkirk, Elisabeth (1990). «A Two-Root Theory of Length». In: Dunlap, Elaine; Padgett, Jaye (eds.). University of Massachusetts Occasional Papers in Linguistics 14: Papers in Phonology. Amherst, MA: Graduate Linguistic Student Association, pp 123-171. 
Steele, Jeffrey; Auger, Julie (2002). «A Constraint-Based Analysis of Intraspeaker Variation: Vocalic Epenthesis in Vimeu Picard». In: Satterfield, Teresa; Tortora, Christina M.; Cresti, Diana (eds.). Current Issues in Romance Languages: Selected Papers from the 29th Linguistic Symposium on Romance Languages (LSRL), Ann Arbor, 8-11 April 1999. Amsterdam: John Benjamins, pp. 317-335.

Vasseur, Gaston (1998). Dictionnaire des Parlers Picards du Vimeu (Somme) avec Considération Spéciale du Dialecte du Nibas. Nouvelle Édition Augmentée d'un Index Français-Picard. Fontenay-sous-Bois: Sides.

Zoll, Cheryl (1998). Parsing below the Segment in a Constraint-Based Framework. Stanford: CSLI Publications. 